\title{
Intensive Case Management of High-Risk Patients in a Family Medicine Residency Setting
}

\author{
Stephen G. Friedhoff, $M D$
}

Background: As the health care system evolves, health care delivery systems have begun to share risk for the care of patient populations. The prototype for such a system has long been the uncompensated care population in a hospital's service area. This article describes a successful case management pilot program in a family medicine residency setting.

Metbods: Nineteen high-risk patients were cared for by a case management team for a period of 3 to 4 months. The case management team consisted of a medical director, 2 resident assistant medical directors, 1 registered nurse case manager, and 1 social worker.

Results: Case management resulted in an annualized decrease of 51 percent of inpatient days and 46 percent of charges. This resulted in an annualized savings of $\$ 166,083$ in charges to the health care system.

Conclusion: Intensive case management of the sickest of the sick results in a substantial reduction in morbidity and cost. Family medicine residency programs are ideally situated to oversee case management of this population and potentially other populations in a shared-risk environment. ( $\mathrm{J}$ Am Board Fam Pract 1999;12:264-9.)

Risk contracting has become commonplace between managed care organizations and health care systems. Simply put, risk contracting involves providing a global capitation to a health care delivery system in exchange for providing comprehensive health care to a predetermined population. The health care system then becomes at risk in that only a fixed number of dollars is available to care for this population. To survive such an arrangement, health care systems must not only control costs but also manage outcomes to prevent recurrent hospitalizations and emergency department visits. Given the cost pressures in managed care, these organizations recognized the need for disease management some time ago.

To some hospitals the concept is nothing new. Many hospitals have been at risk for an uncompensated care population for some time. Uncompensated care reimbursement, if any, is a fixed amount that is often woefully inadequate for caring for the designated population. As are most other revenue sources for hospitals, this reim-

Submitted, revised, 19 February 1999.

From the Family Practice Residency Program, Memorial Hospital of Burlington County, Mount Holly, NJ. Address reprint requests to Stephen Friedhoff, MD, Memorial Hospital of Burlington County Family Medicine Residency Program, 175 Madison Ave, Mount Holly, NJ, 08060 bursement has been shrinking while health care costs continue to rise for this population.

The difficulty of planning care management for uncompensated care increases dramatically when one considers the demographics of the population. Frequently patients seeking uncompensated care are of lower socioeconomic status, are less educated, lack transportation, and have a high rate of smoking, substance abuse, and chronic disease. Their care is often episodic, and patients use emergency departments as their primary care sites. In the past health care systems have devoted little attention to this population, reinforcing the episodic nature of their care. Furthermore, their behavior is perpetuated by their experience of the typical charity clinic, where patients might wait months for an appointment, wait all day to be seen, and leave with prescriptions for drugs they cannot afford and instructions they do not understand.

The cost of this population to a health care system is great, particularly as operating margins diminish. An analysis at Memorial Hospital of Burlington County, Mount Holly, NJ, revealed an alarming increase in charges for the uncompensated care population during the last several years. For this reason the hospital gave the family practice residency faculty the task of devising a way to control the costs of this population. Although the 
idea of case managing such a broad population initially seemed overwhelming, the faculty sought ways to determine where the dollars were being spent and what target populations might best benefit from any interventions.

To research the costs associated with this population, inpatient charts were reviewed to ascertain whether any common factors would help categorize an initial target population. The most common diseases were not surprising and included diabetes, chronic obstructive pulmonary disease (COPD), peripheral vascular disease, substance abuse, and mental illness. Overall, however, the illnesses associated with these patients were extremely diverse. One important observation was made-relatively few patients accounted for a disproportionately large cost.

Once it became clear that only a few patients generated such a large cost, the decision was made to target this small group of patients as a pilot project. Although the ultimate goal was eventually to manage a larger population (ultimately not only treat the sick patients, but prevent the healthy patients with diabetes, hypertension, and other chronic illnesses from becoming sick), it was important to prove the value of such a project with a smaller population given the limited resources at the residency's disposal. In effect, the sickest of the sick patients were selected as the target population.

\section{Types of Case Management}

Conceptually the residency faculty distinguished case management of this population from classic disease state management. In disease state management, populations with such diseases as diabetes are cared for according to algorithms in a multidisciplinary fashion with the goal of improving and maintaining health through prevention and treatment of illness. Although disease state management can be customized, it is designed to maximize outcomes for a large group of similar patients. The target population for this study was so small and diverse, that disease case management in the classical sense would have been ineffective.

The different types of case management can be visualized using a pyramid model. The base of the pyramid represents the foundation of primary care. Here are the healthy patients for whom risk reduction can have the greatest impact. Interventions, such as immunizations, lipid monitoring, and smoking cessation, have low costs per patient but yield tremendous morbidity and cost reductions when implemented on a large scale.

The middle of the pyramid is classical disease state management, encompassing patients with established but stable diseases (examples include the poorly controlled diabetic patient who, thus far, has been free of complications, and the smoker who has had the first serious exacerbation COPD). Frequently this homogeneous population can be approached in an algorithmic fashion, using such techniques as diabetes education, dietary advice, and laboratory monitoring. These patients make up a group of moderate size who require moderate effort for interventions that result in a modest long-term benefit per patient. Given the size of the group, however, the total cost reduction will still be substantial. This form of disease management has been proved in some settings to improve quality of life and lower costs. ${ }^{1}$ Ideally, these programs are evidence-based and involve multidisciplinary teams. ${ }^{2}$

At the top of the pyramid is a smaller group of patients with well-established diseases and a high rate of morbidity. Because of the complexity of their diseases and frequent psychosocial handicaps, they require a highly individualized and multidisciplinary approach. Although their population is small, they require considerable resources for effective management, but the potential yield is great in terms of decreased morbidity and cost per patient.

\section{Methods}

The team for the pilot case management project required essentially no new resources beyond what was already available in the residency facility. The team consisted of the medical director, 2 resident assistant medical directors, 1 social worker, and 1 case manager.

The medical director was a member of the residency faculty. Assisted by 2 resident medical directors, the medical director's responsibilities included acting as a consultant for the case manager and liaison to the primary care physician, monitoring the efforts of the case manager and the case management team, conducting weekly case management meetings with the team, and acting as physician liaison to other departments involved in case management. The resident assistant medical directors were active participants in both the selection process and ongoing case management. 
Table 1. Comparison of Patient Variables Before Case Management in 1997 and During Case Management in 1998 (annualized).

\begin{tabular}{lcc}
\hline Patient Variables & 1997 Actual & 1998 Annualized \\
\hline Charges & $\$ 359,000$ & $\$ 193,000$ \\
Admissions & 12 & 16 \\
Inpatient days & 164 & 80 \\
\hline
\end{tabular}

The social worker was already a member of the residency center and redirected some of her time to the program. The social worker's responsibilities included assisting patients with their application for alternate financial assistance and indigent drug programs, arranging transportation, and coordinating with hospital and community social workers, when necessary. Patients frequently required assistance completing applications for these services because of language barriers and illiteracy or because they had difficulty getting transportation to the clinic. The social worker's efforts were critical to overcoming these barriers. The social worker also provided short-term counseling services to patients who did not qualify for mental health benefits.

The case manager was a part-time registered nurse who served as clinical coordinator of our staff. She increased her time by 8 hours per week to participate in the program. The case manager coordinated every aspect of care for patients in the program. She communicated regularly with patients, primary care physicians, specialist physicians, home care specialists, and the rest of the case management team. The case manager's involvement included ongoing health status assessment, completion of quality-of-life surveys, and frequent telephone calls to detect potential medical problems at an early stage. The case manager provided patient education, coordination of primary care and specialist visits, and assessment of medication compliance.

The team received referrals from primary care physicians and preceptors in the residency office. All new uncompensated inpatient admissions were reviewed as well. Approximately three to five cases were reviewed weekly during the 3 -month period. When a referral was received, one of the medical directors would review the chart and determine whether the patient was an appropriate candidate for intensive case management.
Selection criteria for participation in the program included frequent hospitalizations, at least one chronic disease, and psychosocial risk factors (including noncompliance, financial stressors, and so on). Initially a point system to define the level of medical risk was considered, but because of the small size of the study, such a system would likely not have been meaningful.

Once the medical directors decided that a patient was appropriate for the program, both the case manager and the social worker interviewed the patient. The patient's history, problems, and needs were then discussed at a weekly case management conference involving the entire team. A care plan was created for the patient, and individual responsibilities were delegated to the appropriate team members. The patient's case could be reviewed as needed but no less often than monthly.

Interestingly, most of the interventions were basic. The most common interventions included frequent telephone contact, arrangements for transportation, application to indigent drug programs, and provision of medications.

\section{Results}

During the period of January to April of 1998, 19 patients were enrolled in the case management program. At the conclusion of the case management period, participant utilization data were reviewed. Most patients were cared for by the case management team for 3 to 4 months. Two patients were enrolled late and were in the program for only 1 month. One patient qualified for Medicaid after 1 month in the program. A summary of the results appears in Table 1. Data for specific patients appear in Table 2.

All 1997 inpatient and outpatient charges were totaled for patients involved in the case management program. Next, all charges for patients involved in the case management program were totaled for the study period of January 1998 to April 1998 and annualized to create total projected charges for 1998. The annualized charges for 1998 included the cost of the case management team. When the 2 years were compared, case management resulted in a projected reduction in charges of 46 percent $(\$ 166,083)$ for 1998.

Similar comparisons were made of inpatient days. Inpatient days were reduced by 51 percent (164 days for 1997 compared with 80 days for annualized 1998). Interestingly, the number of pro- 
Table 2. Summary of Financial and Utilization Data for the 19 Patients Who Were in the Case Management Program (1998 Annualized Based on 3 Months' Data).

\begin{tabular}{|c|c|c|c|c|c|c|c|c|}
\hline \multicolumn{5}{|c|}{ Financial Data (\$) } & \multicolumn{4}{|c|}{ Utilization Data } \\
\hline Patient & $\begin{array}{c}1998 \\
\text { Charges } \\
\text { During } \\
\text { Case } \\
\text { Management }\end{array}$ & $\begin{array}{c}1998 \\
\text { Annualized } \\
\text { Charges } \\
\text { with Case } \\
\text { Management }\end{array}$ & $\begin{array}{c}1997 \\
\text { Actual } \\
\text { Charges }\end{array}$ & $\begin{array}{c}\text { Annualized } \\
1998 \\
\text { vs } 1997 \\
\text { Variance }\end{array}$ & $\begin{array}{c}1998 \\
\text { Admissions } \\
\text { During } \\
\text { Case } \\
\text { Management }\end{array}$ & $\begin{array}{c}1998 \\
\text { Inparient } \\
\text { Days } \\
\text { During Case } \\
\text { Management }\end{array}$ & $\begin{array}{c}1997 \\
\text { Admissions }\end{array}$ & $\begin{array}{c}1997 \\
\text { Inpatient } \\
\text { Days }\end{array}$ \\
\hline A & 240 & 960 & 50,113 & $(49,153)$ & 0 & 0 & 1 & 16 \\
\hline B & 0 & 0 & 46,395 & $(46,395)$ & 0 & 0 & 1 & 20 \\
\hline $\mathrm{C}$ & 158 & 632 & 30,788 & $(30,156)$ & 0 & 0 & 1 & 10 \\
\hline $\mathrm{D}$ & 0 & 0 & 28,457 & $(28,457)$ & 0 & 0 & 1 & 34 \\
\hline $\mathrm{E}$ & 570 & 2,280 & 27,818 & $(25,538)$ & 1 & 1 & 1 & 3 \\
\hline F & 2,162 & 8,648 & 23,386 & $(14,738)$ & 0 & 0 & 1 & 10 \\
\hline $\mathrm{G}$ & 208 & 832 & 23,246 & $(22,414)$ & 0 & 0 & 1 & 11 \\
\hline $\mathrm{H}$ & 140 & 560 & 14,318 & $(13,758)$ & 0 & 0 & 1 & 22 \\
\hline I & 61 & 244 & 11,439 & $(11,195)$ & 0 & 0 & 1 & 5 \\
\hline $\mathrm{J}^{*}$ & 4,070 & 48,840 & 81,519 & $(32,679)$ & $0^{\dagger}$ & 0 & 1 & 26 \\
\hline $\mathrm{K}$ & 12,052 & 48,208 & 6,306 & 41,902 & 1 & 4 & 0 & 0 \\
\hline $\mathrm{L}^{\ddagger}$ & 43 & 516 & 1,811 & $(1,295)$ & 0 & 0 & 0 & 0 \\
\hline$M^{\ddagger}$ & N/A & 0 & N/A & N/A & $0^{+}$ & 0 & 1 & 5 \\
\hline $\mathbf{N}$ & 15,366 & 61,464 & 1,959 & 59,505 & 1 & 9 & 0 & 0 \\
\hline $\mathrm{O}$ & 1,343 & 5,372 & 7,493 & $(2,121)$ & 1 & 6 & 1 & 2 \\
\hline $\mathbf{P}$ & 1,229 & 4,916 & 4,557 & 359 & $0^{\dagger}$ & 0 & 0 & \\
\hline $\mathrm{Q}$ & 109 & 436 & 0 & 436 & $0^{\dagger}$ & 0 & 0 & 0 \\
\hline $\mathrm{R}$ & 248 & 992 & 0 & 992 & $0^{+}$ & 0 & 0 & 0 \\
\hline S & 2,197 & 8,788 & 166 & 8,622 & 0 & 0 & 0 & 0 \\
\hline Total & $\$ 40,196$ & $\$ 193,688$ & $\$ 359,771$ & $(\$ 166,083)$ & 4 & 20 & 12 & 164 \\
\hline
\end{tabular}

*Patient in program for 1-month period, converted to Medicaid.

†Patient entered case management program after hospital admission in 1998.

₹Patient entered program in April-May 1998; data annualized based on 1 month.

jected admissions actually increased. During 1997 there were 12 admissions among the study group, whereas in 1998 the number of annualized admissions was 16 . Although the small sample size could certainly have accounted for this variation, it became clear during the study that exacerbations of disease were being recognized early, which could explain a pattern of more frequent admissions with shorter lengths of stay.

During the case management period, charges directly related to case management were detailed as well. These charges included time spent by the case management team, additional home care beyond that which would typically be provided, transportation, medications, and so on. Interestingly, case management-related charges ac- counted for only 16 percent of the total charges for the 19 patients during case management.

\section{Discussion}

As previously noted, most of the team's interventions involved patients' basic life needs. The simple act of calling patients once or twice a week to check on their medication supply, finger-stick blood glucose results, or peak expiratory flow rates had a profound effect. Hospital admissions were frequently avoided (or of shorter length of stay) by discovering that a patient was out of insulin, was in the early phases of a COPD exacerbation, or was not taking medications. Surprisingly, most of these illnesses were recognized early as a result of a routine telephone call generated by the case manager 
rather than the ill patient. 'This factor was believed to account for the paradox of increased admission rate but decreased admission days.

Less quantifiable was a perceived increase in compliance in many patients. Some patients who had previously drifted in and out of hospitals and emergency departments seemed to act less hopeless and helpless now that someone cared about their well-being. This feeling cared for appeared to have a very real effect on the quality of life of some patients. At the least, most team members appreciated an increase in patient compliance.

Certain anecdotal success stories are worth noting as well. One patient, a young woman, had steroid-dependent lupus erythematosus, type 1 diabetes, bilateral osteonecrosis of the hips, and renal failure. Despite serious disability and multiple admissions to the hospital, accounting for more than 70 days in 1997 , the patient was unable to complete a disability application, for the most part because of her extreme noncompliance as an outpatient. Her lack of health insurance only contributed to her poor follow-up with physicians and medication. With extensive assistance from the case management social worker, the patient was able to complete the application successfully and obtain medications, transportation, and medical benefits. At least 1 other patient required a similar intervention. In the latter case, the social worker hand delivered the application to the patient and assisted with its completion. Ironically, both of these patients clearly qualified for disability in 1997 but never completed the application despite involvement of traditional inpatient social services.

Other patients had similar success stories. Two patients eventually felt well enough to return to work. Eleven patients were enrolled in indigent drug programs and received medications they could previously not afford. Five patients who lacked transportation for physician visits were enrolled in local transportation programs. Previously, these patients did not receive any health care until they were ill enough to require ambulance transportation to the emergency department for sporadic care or hospital admission.

For the most part, the patients enrolled in the program were receptive and grateful for the program. One potential drawback to this case management approach could be increased dependency and feelings of entitlement in this population. Unfortunately, there was little opportunity to increase independence among the patients. As noted, however, 2 of 19 patients did ultimately return to employment.

Admittedly, the selection criteria were highly dependent on clinical judgment. While patients were evaluated for such characteristics as frequent hospitalizations, one or more chronic illnesses, and psychosocial stressors, the selection process was still somewhat subjective. If these programs were to be adopted on a large scale, presumably a point system based on similar criteria would need to be developed to define medical risk.

As previously noted, case management-related charges accounted for only 16 percent of total charges for all 19 patients. It seems that the financial investment in case management is relatively small compared with the cost of caring for these patients overall.

Obviously the statistical significance of the data is highly questionable. Given the limited resources, it was possible to enroll a maximum of 19 patients at any given time. With only 3 to 4 months of data on each patient, it is difficult to project accurately the annual reductions in health care utilization and charges that could be attributed to the program. Nevertheless, the magnitude of the reduction in charges is quite compelling. In addition, all patients obtained a higher level of medical care through indigent drug programs, increased transportation, access to physicians, disease education, and early recognition of morbidity. Although such gains are difficult to quantify, it is difficult to imagine that they would not affect quality of life or quality of care. In contrast to these findings, however, one literature review of nine case management programs reported no significant cost savings and noted that no programs involving generalists or targeting general disease conditions reported a positive effect. ${ }^{3}$ Further study with greater resource allocation and more patients would help clarify the effects of a case management program similar to the one described here.

\section{Conclusion}

An efficient case management program was conducted in a family medicine residency setting with a minimum of resources. Although our project did not begin as a study, the results were so compelling that they are worth reporting for further 
investigation. Intensive case management of the sickest of the sick yielded tremendous benefits in reducing morbidity, hospital days, and charges. Developing these case management skills by health care systems could be critical in a risk-sharing environment.

Donna Wharton, RN, Kim Tarshis, LCSW, MSW, Horatio Jones, $\mathrm{MD}$, and Eric Cutti, MD, were members of the case management team. Jeffrey Snyder, MBA, assisted with data gathering and analysis. Edward A. Gilkey, MD, performed the initial chart review to profile the highest-risk patients.

\section{References}

1. Aubert RE, Herman WH, Waters J, Moore W, Sutton $\mathrm{D}$, Peterson BL, et al. Nurse case management to improve glycemic control in diabetic patients in a health maintenance organization. A randomized controlled trial. Ann Intern Med 1998;129:605-12.

2. Ellrodt G, Cook DJ, Lee J, Cho M, Hunt D, Weingarten S. Evidence-based disease management. JAMA 1997;278:1687-92.

3. Ferguson JA, Weinberger $M$. Case management programs in primary care. J Gen Intern Med 1998; 13:123-6. 